\title{
Towards Modern Depressive Disorder: Professional Understanding of Depression in Interwar Britain
}

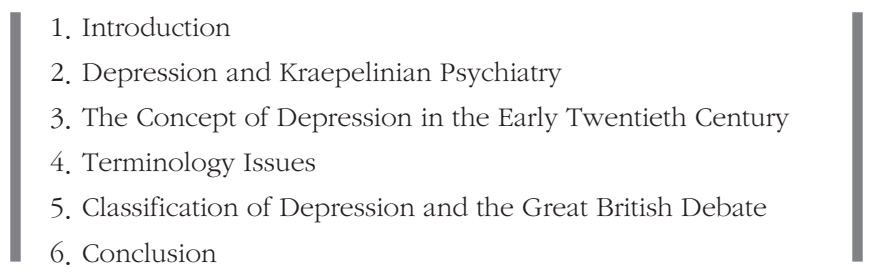

\section{Introduction}

There has been a prolonged controversy over the relation between melancholia and depression. The major question is whether we can equate depression of today with melancholia, a very old diagnosis with Greek origins. Proponents of the continuity view, including Stanley W. Jackson, Allan V. Horwitz, Jerome Wakefiled and Somogy Varga, argue that modern depressive disorder can be seen as the same condition as melancholia (Jackson, 1986; Misbach \& Stam, 2006; Horwitz \& Wakefield, 2007; Varga, 2013). Jackson, for instance, insists that despite all the

\footnotetext{
* Lecturer, Department of Western History, Seoul National University, Korea / E-mail: hjeanhwang@naver.com
} 
HWANG Hye Jean : Towards Modern Depressive Disorder: Professional Understanding of Depression in Interwar Britain

differences in the symptoms of melancholia affectivity has remained as its core feature, and finds a 'remarkable consistency' between longlived melancholia and twentieth-century depressive disorder (Jackson, 1986: 188-246). On the contrary, discontinuity view supporters, such as German E. Berrios, Roy Porter, Åsa Jansson and Jennifer Radden, oppose such identification, arguing that the differences between melancholia and depression 'preponderate over the similarities' (Berrios, 1988; 1995; 1996; Radden, 2009; Jansson, 2011; 2013). Berrios contends that even in the Napoleonic period low mood had not been considered as a critical symptom of melancholia and that it was only in the nineteenth century when melancholia came to be considered as an affective disorder (Berrios, 1996: 293-299). Jansson argues that mental illness should be interpreted as 'specific to a particular historical moment' and criticizes continuity views that result from a misunderstanding of a "continuity of language' (Jansson, 2011: 394-395).

This study begins with the assumption of Jansson and discontinuity view supporters: what constitutes melancholia and depression changes over time. It aims to examine the psychiatric concept against a specific historical background, interwar Britain. To be more specific, it traces the way in which depression was understood, interpreted, classified and applied by British psychiatrists, mainly by analyzing expert literature, such as journals and textbooks. The analysis is expected to illustrate the status of depression as a discrete mental disorder in this period, in relation to its concept, terminology and classification. Also, it will suggest a proper way to perceive this stage in the long history of melancholia and depression.

Although this research focuses on a specific psychiatric diagnosis, 
HWANG Hye Jean : Towards Modern Depressive Disorder: Professional Understanding of Depression in Interwar Britain

depression, it also helps us have a better understanding of the psychiatry itself during the interwar years. As acknowledged, psychiatry, a 'Cinderella of medicine', had struggled to establish itself as a respectable profession since Victorian period (Long, 2014: 13). Historians with special interests in British psychiatry praise the major progress made in the early twentieth century, and some of them put emphasis on the First World War and the experience of shell-shock as its crucial factor. ${ }^{1)}$ Notably, Elaine Showalter regards the Great War as a turning point when the transition from psychiatric Darwinism to Modernism took place (Showalter, 1987: 18-19, 195-219). Examining the concept of depression in the early and mid twentieth century gives us a chance to check the validity of such explanation of British psychiatry.

\section{Depression and Kraepelinian Psychiatry}

In tracing how British psychiatrists in the early twentieth century understood and explained melancholia and depression, Emil Kraepelin and his serial Textbook on Psychiatry provide a reasonable starting point.

1) On explaining the characteristics of what British psychiatry achieved in the first half of the twentieth century, historians attribute the impetus to various and different factors. Many researchers, including Showalter, put emphasis on the Great War and the experience of shell-shock. For instance, Joan Busfield notes that the shell shock cases changed the attitude to psychoanalysis and, furthermore, to psychiatry among the British (Busfield, 2000: 644-645). Kathleen Jones argues that mental health and psychiatry as a profession in charge of it came to 'acquire a new and wider significance' during the War (Jones, 1993: 141-142). Others stress the prevailing social and cultural environment as an accelerator for psychiatric development and its application. Mathew Thomson has emphasized the importance of what happened outside of "professional formation and theoretical advance' in establishing the new understanding of mental health (Thomson, 2006: 5-9). Meanwhile, Roy Porter points out that the main drive for advancement came from a combination of the self-generated motivation of psychiatry and the public's growing interest in social science (Porter, 1996: 385). 
HWANG Hye Jean : Towards Modern Depressive Disorder: Professional Understanding of Depression in Interwar Britain

He devised solutions to many of the problems related to the diagnosis, including its nomenclature and taxonomy. The so-called 'founder of modern psychiatry' contributed greatly to the development of psychiatry in the early twentieth century by recasting the way we view major mental diseases and setting up a new framework for naming and categorizing them (Shorter, 2005: 156). He made his reputation as a leading psychiatrist by publishing a succession of editions of his Textbook, the first edition being released in 1883 and the ninth one in 1927 . This series, covering almost a half century, reveals how his view on every psychiatric issue had been developed and adapted over the time. ${ }^{2)}$ Among the successive editions, the sixth published in 1899 has been considered as the most important and is mentioned most frequently. In this edition, Kraepelin finally cleared up the confusion over nomenclature and classification of mental disorders, both having challenged psychiatrists throughout the century. He put all kinds of psychotic illness into two categories, dementia praecox and manic-depressive insanity, depending on the involvement of any affective component, which has been appraised as a 'dramatic compression'. This nosological framework was to lay the foundation for the Diagnostic and Statistical Manual of Mental Disorders,

2) Kraepelins' Textbook series illustrated the development of the author's view and the evolution of general psychiatry during the late nineteenth century and the early twentieth century, because it had been published over several decades from 1883 to 1927. However, the content also caused confusion, and sometimes conflict, over how to understand it. 'Involutional melancholia' is a typical example. Kraepelin's revision caused confusion among both psychiatrists back then and historians later. Meanwhile, as German E. Berrios has pointed out 'selective reading' of Kraepelin's work contributed to misunderstanding and misinterpretation of his main concepts, particularly affective disorder. According to him, 'the history of the affective disorders after 1910 is no more than the analysis of the fragmentation of the Kraepelinian notion'(Berrios, 1995: 392393; 1996: 300, Shorter, 2005: 175-176). 
HWANG Hye Jean : Towards Modern Depressive Disorder: Professional Understanding of Depression in Interwar Britain

and the International Classification of Disease, both of which are still in intensive use all over the world (Shorter, 1997: 106-107).

In establishing twentieth-century depression, too, he played a key role. Firstly, he put an end to the long standing confusion about nomenclature, by overseeing the transition of terminology from melancholia to depression. Melancholia enjoyed an official position as a diagnostic term throughout the nineteenth century despite increasing dissatisfaction with its loose usage. Meanwhile, depression was either considered at best as a synonym for melancholia or used mostly in order to describe low mood state as a symptom of those suffering from various mental illnesses. The latter, however, was moving towards its modern meaning and usage during the Victorian era (Lawlor, 2012: 128). Finally, in 1896, Kraepelin abandoned melancholia as a diagnosis and introduced depression as its replacement in the fifth edition of the Textbook. ${ }^{3)}$ Through his influence upon European psychiatry, depression was elevated to an official diagnostic term and the protracted terminological changeover seemed to be concluded. Secondly, Kraepelin suggested a new framework to classify depression and, as its superordinate concept, affective disorder. As mentioned earlier, in the sixth edition of his Textbook, he proposed two umbrella concepts covering all types of mental illness; dementia praecox and manic-depressive insanity. The latter included manic states, depressed states and mixed states, all of which exhibited pathological emotional states as a core symptom (Jackson, 1986: 189). Depression

3) In the United States, Adolf Meyer led the shift from melancholia to depression around the turn of this century. According to an article, he was 'desirous of eliminating the term melancholia, which implied a knowledge of something that we did not possess. ( $\cdots)$ If, instead of melancholia, we applied the term depression to the whole class, it would designate in an unassuming way exactly what was meant' (Jackson, 2008: 445). 
HWANG Hye Jean : Towards Modern Depressive Disorder: Professional Understanding of Depression in Interwar Britain

was grouped into three types in a sequence of severity:4) simple depression, depression with delusions and hallucination, and stuporous condition (Kraepelin, 1921). The nomenclature and taxonomy suggested by Kraepelin exerted a critical effect on the way in which European psychiatrists recognized depression (and affective disorder) thereafter, and largely decided the path that the psychiatric notion (and its related concepts) followed throughout the early twentieth century, which will be dealt with in detail later in this article.

Before illustrating the early-twentieth-century history of depression, it should be mentioned that Kraepelin faithfully followed the tradition of nineteenth-century psychiatry and handed many of its achievements over to twentieth-century medicine. In terms of the ways in which questions were raised and the answers found, he held fast to Victorian psychiatry. Dissatisfaction with this terminology issue was not only felt by Kraepelin, but had also been expressed by his predecessors in this medical branch throughout the nineteenth century. As early as 1820, Jean-Etienne Dominique Esquirol revealed deep discontent at melancholia, and replaced the old term with a new concept, lypemania, the first attempt to introduce a substitute for the archaic term, melancholia. ${ }^{5)}$ Also, the great

4) The suggested categorization of depression was never fixed one. Kraepelin himself changed the sub-groups of depression over time, as he did with many other diagnostic concepts. For instance, in the eighth edition of his Textbook, he grouped the disorder into six, again according to severity and accompanied symptoms: simple depression; stupor; melancholia gravis; paranoid depression; fantastic depression; and delirious depression.

5) Jean-Etienne Dominique Esquirol (1772-1840) is said to be the 'founder of the French tradition of psychiatric nosology'. The early years of his career as a psychiatrist had been under the strong influence of Philippe Pinel. Esquirol joined the Salpêtrière Hospital in 1811, and remained there until 1825 when he was appointed as a chief physician at Charenton National Asylum. Esquirol initiated France's first course of psychiatry lectures in 1817 and was deeply involved with education throughout his career, and participated 
HWANG Hye Jean : Towards Modern Depressive Disorder: Professional Understanding of Depression in Interwar Britain

interest in the classification of mental illness was pervasive throughout the century, and most prominent psychiatrists involved themselves eagerly in taxonomic work, including Wilhelm Griesinger, Richard von KrafftEbing, and Karl Ludwig Kahlbaum, all directly affecting Kraeplinian nosology. ${ }^{6}$ In terms of methodology, too, he followed the path paved by nineteenth-century psychiatrists. He was under the influence of a strong tradition of descriptive psychopathology, which was developed primarily by Esquirol and carried on by Griesinger and Krafft-Ebing (Berrios, 1996: 15-31). Such a methodology offered Kraepelin a solid ground, as his study was rooted in the massive volume of descriptions collected from his practice. His longitudinal approach to insanity was inherited from senior German psychiatrists, notably Kahlbaum. Kraepelin considered the time dimension as an important factor in understanding mental illness and paid close attention to the course of a disorder, according to his own language, 'prognosis' (Jackson, 1986: 449). Therefore, Kraepelinian psychiatry should be understood as being an extension of the nineteenth-century medical tradition, which does not necessarily deny his own contribution and achievement. That he clung to the conventions of Victorian psychiatry is as true as the appraisal that he opened the door for twentieth-century modern psychiatry. As a result, it means that in order to appreciate the early-twentieth-century

in the reform of asylums. However, he has been 'mainly remembered for his attempt to refine psychiatry diagnosis with such terms as monomania and lypemania' (Berrios, 1996: 303-304; Shorter, 2005: 100-101).

6) The need to re-classify affective disorders during the nineteenth century had various origins. There was the taxonomic impetus driving the whole of medicine; an internal need to tidy up the nosology of psychiatry; the influence of faculty psychology; the ever looming presence of degeneration theory; and, late in the century, the need to identify homogeneous clinical groups for neuropathological study, particularly in relation to the differential diagnosis between melancholia and dementia (Berrios, 1995: 387-388). 
HWANG Hye Jean : Towards Modern Depressive Disorder: Professional Understanding of Depression in Interwar Britain

professional understanding of melancholia and depression, which owed much to Kraepelinian psychiatry, we need to take the nineteenth-century psychiatric tradition and its achievements into serious consideration.

\section{The Concept of Depression in the Early Twentieth Century}

In examining the history of depression in the early twentieth century, its definition could be the best departure point. Under the strong influence of Kraepelinian taxonomy, depression, with mania, was usually explained as a sub-category of manic-depressive psychosis. In the eighth edition of the Textbook, Kraepelin claimed that manic-depressive insanity "includes on the one hand the whole domain of so-called periodic and circular insanity, on the other hand simple mania, the greater part of the morbid states termed melancholia and also a not inconsiderable number of cases of amentia'. As sub-types of the umbrella concept, he distinguished manic states "with the essential morbid symptoms of flight of ideas, exalted mood, and pressure of activity', whereas depressive states 'with sad or anxious moodiness and also sluggishness of thought and action' (Kraepelin, 1921: 1-4). A Text-Book of Psychiatry for Students and Practitioners, the first edition of which was published in 1927 by D. K. Henderson and R. D. Gillespie and gained a huge success immediately, took almost the same format. Even though Henderson and Gillespie were against Kraepelinian psychiatry in many ways and were more inclined towards American rather than Continental psychiatry, they applied the concept of manic-depressive psychosis as it had been suggested by its originator and defined it as 'disorders of affect' (Henderson \& Gillespie, 1927: 116). 
HWANG Hye Jean : Towards Modern Depressive Disorder: Professional Understanding of Depression in Interwar Britain

Most definitions of melancholia, depression or depressive state centered on the way in which the disorder manifested itself, namely symptoms. In his Textbook, Kraepelin described that "we distinguish ( ..) melancholia or depressive states with sad or anxious moodiness and also sluggishness of thought and action' (Kraepelin, 1921:3-4). Henderson and Gillespie recognized 'a triad of symptoms' present in all depression cases regardless of their severity, which were difficulty in thinking, mood depression and psychomotor retardation (Henderson \& Gillespie, 1927: 132-133). Aubrey Lewis of the Maudsley Hospital, who actively engaged himself in publishing a series of articles on depression and melancholia from the early 1930s, suggested an exhaustive definition. He understood 'depressive state' as 'a condition in which the clinical picture is dominated by an unpleasant affect, not transitory, without evidence of schizophrenic disorder or organic disorder of the brain, and in which moreover, the affective change appears primary, not secondary to other symptoms of ill-health'(Lewis, 1934: 277). All of them stressed the affective feature of depression as a primary symptom.

The early-twentieth-century professional understanding of depression owed much to Victorian psychiatry. Throughout the nineteenth century melancholia went through a series of critical changes to acquire the main features which were noticeable in the aforementioned early-twentiethcentury definitions and later were to comprise 'modern' depression, as we understand it today, in the late twentieth century. It was mania that had adjusted itself and narrowed down its boundary first to reach its modern meaning. In this sense, Esquirol and his lypemania were often considered as signaling the beginning of the modern understanding of a mental disorder with an ancient origin (Shorter, 2005: 79). In an essay 
HWANG Hye Jean : Towards Modern Depressive Disorder: Professional Understanding of Depression in Interwar Britain

published in 1820, this French psychiatrist introduced the new concept as a replacement of melancholia which he disdained mainly due to its deep association with humoral theories. He also emphasized affective and emotional nature of the disorder, the most significant change that happened to the understanding of melancholia according to Berrios (Berrios, 1995: 385). Thenceforth symptoms unrelated to emotion were gradually eliminated from the description of melancholia and depression; notably, delusion which had been considered as one of the main features lost its importance. From the mid-nineteenth century, definitions of melancholia were renovated, and related concepts which were called affective disorders in the next century were established. In the period between Esquirol and Kraepelin some assumptions were settled within expert circles: that the disorder was a 'primary' pathology of affect; was periodic in nature; had brain representation; and was hereditary and genetic in origin (Berrios, 1995: 387). Late in this century, Kraepelin took these features, adding or subtracting almost nothing, and passed them on to twentieth-century psychiatry.

Therefore, with regard to its definition, twentieth-century depression did not vary much from its predecessor, nineteenth-century melancholia. The similarity between the two can be easily confirmed. A Dictionary of Psychological Medicine, so-called Tuke's Dictionary, published in 1892, shows that consensus had already been reached among the specialists at the end of the century (Lawlor, 2012: 128). In this Dictionary, melancholia was identified as 'a disorder characterized by a feeling of misery which is in excess of what is justified by the circumstances in which the individual 
HWANG Hye Jean : Towards Modern Depressive Disorder: Professional Understanding of Depression in Interwar Britain

is placed' (Tuke, 1892: 787-796). ${ }^{7}$ The core feature lay in the extreme emotional state, illustrating the most important shift that melancholia had undergone during the Victorian age (Berrios, 1996: 298-301; Jackson, 2008: 448-456). Texts written in the early twentieth century showed little difference. In an article published in the Lancet, in 1901, melancholia was identified with the 'emotion of fear, ${ }^{8}$ ) and in another article issued in 1911, George M. Robertson, then a physician-superintendent of the Royal Edinburgh Asylum, claimed the disorder should be defined as 'being primarily and fundamentally a disease of depressed or painful emotion'." As we have seen above, the definition of Henderson and Gillespie in the 1920s, and that of Lewis in the 1930s, showed remarkable similarity to them.

Regarding the etiology of depression, late-nineteenth- and earlytwentieth-century psychiatrists most commonly blamed heredity. To begin with, in the eighth edition of his Textbook Kraepelin claimed that 'the causes of the malady we must seek $(\cdots)$ essentially in morbid predisposition'. Subsequently he demonstrated the 'hereditary taint' was responsible for about 80 percent of the cases which he had observed in Heidelberg (Kraepelin, 1921: 165). In the aforementioned article in the Lancet Robertson argued that the attacks were "largely due to the inheritance of an unstable nervous system, ${ }^{10)}$ and Henderson and Gillespie asserted "there is no doubt that hereditary predisposition is the

7) In the Dictionary, however, depression was only considered just as a synonym of melancholia: searching it, there was only one line of explanation, 'see melancholia', a good contrast to the over eleven pages long description of the former terminology.

8) Lancet, 24 August 1901.

9) Lancet, 1 April 1911.

10) Lancet, 1 April 1911. 
HWANG Hye Jean : Towards Modern Depressive Disorder: Professional Understanding of Depression in Interwar Britain

most important predisposing etiological factor' (Henderson \& Gillespie, 1927: 117). Environments or circumstances were often mentioned along with heredity as a 'contributory' factor. ${ }^{11)}$ Similarly, psychic influence, a representative example of which was shock followed by a close relative's death, was not rarely taken into consideration as sparking off individual attacks. Nevertheless, even while they were concerned about external stimuli, early twentieth-century mind doctors were usually obsessed by the internal and innate causes. This can be confirmed by Kraepelin's assertion that "external influences could play a subordinate part in the causation of manic-depressive insanity', and that 'the real cause of the malady must be sought in permanent internal changes, which at least very often, perhaps always, are innate' (Kraepelin, 1921: 177-180).

With reference to gender, almost all psychiatrists believed that women were more vulnerable to mental illness than men, in line with the then widely held belief that depression was a female malady. Female dominance among the patients was confirmed by all text materials dealing with this subject. Kraepelin demonstrated that 'about 70 percent of the patients belong to the female sex' (Kraepelin, 1921: 174). Two decades later, Henderson and Gillespie suggested the same figure in $A$ Text-Book of Psychiatry and stressed that "women are more liable to this disease than men'(Henderson \& Gillespie, 1927: 117). Common explanation for the reason behind the 'obvious' phenomenon was that it had something to do with the reproductive system of female body. Quoting Kraepelin again, 'the processes connected with sexual life, the beginning of the menses, which not infrequently starts the first attack,

11) Lancet, 14 May 1927. 
HWANG Hye Jean : Towards Modern Depressive Disorder: Professional Understanding of Depression in Interwar Britain

parturition and puerperium and also involution, without doubt here play a part' (Kraepelin, 1921: 174).

At least regarding the definition, what we understand as depression can be traced back to the nineteenth century. Berrios's derogation that before its re-conceptualization during the Victorian period melancholia was 'a rag-bag of insanity states whose only common denominator was the presence of few delusions' appears too harsh (Berrios, 1995: 385). In Robert Burton's The Anatomy of Melancholy, published in 1621, sadness, sorrow and fear were at the centre of the experience of melancholia, corresponding to the continuity view (Shorter, 2005: 175). Nonetheless, Berrios's emphasis on the nineteenth-century transformation of melancholia seems convincing. ${ }^{12)}$ In the history of melancholia and depression, the early twentieth century can be interpreted as a period of transition, bridging the nineteenth century when the concept was relaunched and the late twentieth century when modern depression was finally established (Lawlor, 2012: 134).

\section{Terminology Issues}

As we have seen, throughout the nineteenth century psychiatrists agonized over terminology in relation to melancholia and depression. Although they noted growing discontent with the old term, solutions which could be agreed by all were hard to find. Approaching the end of the century, Kraepelin seemed to resolve the confusing situation, by

12) Åsa Jansson, another discontinuity view supporter, emphasizes the contribution of Wilhelm Griesinger to the reconceptualization of melancholia in the nineteenth century (Jansson, 2011: 393-399). 
HWANG Hye Jean : Towards Modern Depressive Disorder: Professional Understanding of Depression in Interwar Britain

making depression an official diagnostic term, replacing melancholia. However, it did not necessarily mean the transition was achieved swiftly. It took a long time for depression to replace melancholia, though historical research assumes that there was little place for melancholia in the twentieth-century psychiatric environment and that depression became dominant as soon as it gained authority as a diagnostic term. For instance, Jackson has declared that with the arrival of the category of manicdepressive insanity melancholia became 'much less prominent' (Jackson, 2008: 445). More recently, Clark Lawlor has written, boldly enough, that 'the death of the Victorian age meant the death of melancholia' (Lawlor, 2012: 134). However, this does not seem to be how it happened in the early twentieth century.

Change came slowly in Britain. The Nomenclature of Disease published by the Joint Committee appointed by the Royal College of Physicians of London provides a good example to illustrate the atmosphere within British psychiatry in the early years of the twentieth century. In its 1906 version the official diagnostic term referring to pathological low mood was not depression but melancholia. ${ }^{13)}$ It is somewhat surprising and perplexing, especially considering that the Nomenclature of Disease authorized Kraepelinian classifying methodology and its basic concepts about manic-depressive insanity for the first time in Britain (Berrios, 1996: 315). Although it was a decade later than Kraepelin had given up melancholia as a diagnosis in the fifth edition of Textbook, the old term was still applied as a formal disease name.

With respect to word frequency, melancholia held the upper hand

13) Royal College of Physicians of London, Nomenclature of Disease (4th edn, London, 1906). 
HWANG Hye Jean : Towards Modern Depressive Disorder: Professional Understanding of Depression in Interwar Britain

over depression well into the early twentieth century too. In major medical journals, the old term appeared more frequently than the new one. For instance, in the Journal of Mental Science, melancholia was used more commonly and frequently as a diagnostic term than depression in the 1900s and 1910s. Specifically, in 1905, melancholia was employed in 42 articles or news items in the journal, but depression in 33, and in 1910 melancholia was applied in 36 items, while depression only in 15. As seen below, it was during and after the Great War that depression preponderated over melancholia in frequency. Taking the Journal of Mental Science as an example once again, only in the late 1910s did depression outstrip melancholia for the first time, and in the next decade it was applied more frequently, sometimes double, compared with the older term. Now the predominance of depression was established.

Table 1. Word Frequency in the Journal of Mental Science Sampled Every Five Years between 1900 and $1940^{14)}$

\begin{tabular}{c|c|c|c}
\hline Year & Melancholia & Depression & $\begin{array}{c}\text { Manic-Depressive insanity } \\
\text { (psychosis) }\end{array}$ \\
\hline 1900 & 73 & 47 & 0 \\
\hline 1905 & 42 & 33 & 1 \\
\hline 1910 & 36 & 15 & 22 \\
\hline 1915 & 20 & 23 & 3 \\
\hline 1920 & 6 & 17 & 13 \\
\hline 1925 & 23 & 48 & 64 \\
\hline 1930 & 49 & 49 & 96 \\
\hline 1935 & 44 & 71 & 21 \\
\hline 1940 & 11 & 39 & 64 \\
\hline
\end{tabular}

14) https://www. cambridge. org/core/journals/the-british-journal-of-psychiatry. Accessed 11 June 2018. 
HWANG Hye Jean : Towards Modern Depressive Disorder: Professional Understanding of Depression in Interwar Britain

However, even under these circumstances, melancholia continued to be given as a diagnosis. In daily practice, surprisingly, it stayed in use as a diagnostic term even after the War. Various kinds of medical records prove how hard and prolonged the transition was. For instance, in the case notes of Holloway Sanatorium well into the 1920s melancholia was still applied as a diagnostic term, often with adjectives, such as 'recurrent' or 'agitated'. In a case book covering female admissions (certified only) between 1924 and 1926, over ten patients were diagnosed as suffering from 'melancholia', and only one was identified as manic-depressive insanity. 'Depression' and 'depressed' were used only for describing patients' state in individual case files, and not applied for diagnosis even in a single case. ${ }^{15)}$ It seems that Holloway Sanatorium followed scrupulously the Nomenclature of Diseases published in 1906 at least up to this point. Such a finding appears to support Berrios's claim that the Nomenclature lasted until the great British debate, which led the British psychiatrists into a stark clash of opinion after 1926, as will be examined later in this article (Berrios, 1995: 398). At the Maudsley Hospital too, which claimed to be an 'innovative' mental institution, melancholia was occasionally applied to diagnosis, although 'depressive state' was favoured most amongst various terminologies synonymous with depression. ${ }^{16)}$

In expert literature, too, melancholia did not disappear completely. When Lewis of the Maudsley published his lengthy clinical survey of the depressive state in 1934, he applied 'melancholia' in the title. In this article, he explained that he meant 'depressive state' by melancholia

15) Holloway Sanatorium, Case Book: Females [Volume 28], LWIHM, Acc. 343440, MS 5161.

16) Maudsley Hospital, Patient Casenotes, BRHAM CFM-067, Case No. 6269. 
HWANG Hye Jean : Towards Modern Depressive Disorder: Professional Understanding of Depression in Interwar Britain

and he used these words interchangeably (Lewis, 1934). On releasing the case materials used for the aforementioned article two years later in the Journal of Mental Science, Lewis used the old term in the title again, this time with no specific explanation about the use of the term (Lewis, 1936). This was despite the fact that the official diagnostic term for the same clinical condition in the Maudsley was not melancholia but depression. ${ }^{17)}$ From the 1930s melancholia was increasingly used with an adjective, 'involutional', rather than being applied alone. ${ }^{18)}$ It was mainly because a debate on another confusing diagnostic concept involutional melancholia', referring to depression at the menopause, failed to reach any consensus within expert circles, and grew into a more serious conflict of opinion, which will be discussed below.

Strangely the wane of the term melancholia witnessed an interesting phenomenon in the late 1920s and 1930s, when ironically the term depression was just beginning to flourish. ${ }^{19)}$ The frequency of the word melancholia in medical journals soared around 1930. In the Journal of Mental Science melancholia appeared only six times in 1920, but 23 in 1925, 49 in 1930 and 44 times in 1935. Although its prevalence was less than that of its successor, depression, it still showed a steep increase. However, it is noteworthy that at this time the word melancholia indicated a different meaning and nuance. In his article 'The Psychological

17) Maudsley Hospital, Medical Superintendent's Annual Report, Year ended 31st January, 1924, BRHAM.

18) Lancet, 21 December 1940.

19) Despite the uncertainties encircling its definition, classification and etiology, depression was already the largest single diagnosis category by the 1920s, and became even more prevalent in the next decade. In the case of the Maudsley Hospital, among the entire patient population between 1923 and 1938, both in-patients and out-patients, over a third (37.5 per cent) was diagnosed with depression. 
HWANG Hye Jean : Towards Modern Depressive Disorder: Professional Understanding of Depression in Interwar Britain

Treatment of Mania and Depression' of 1927 Ernest Snowden of the St. Bartholomew's Hospital distinguished depression and melancholia from each other, signifying severe cases with the latter. ${ }^{20)}$ In 1938, two years after the publication of 'Melancholia: Prognostic Study and Case-Material', Lewis also used melancholia in the same way in his new article 'States of Depression: Their Clinical and Etiological Differentiation'. This time he articulated that 'melancholia was for acute cases' (Lewis, 1938: 875-878). In a way, this change can be related to the fierce debate on the nosology of affective disorder focusing on severity during the 1920s and 1930s, which will be illustrated below. It is difficult for us to check how many professionals agreed with the use of the old term in this way. However, it is reasonable to assume that it did not lessen the confusion relating to the application of the words, but rather aggravated the situation within expert circles.

\section{Classification of Depression and the Great British Debate}

Among various issues related to depression, it was classification of the affective disorder that puzzled British psychiatrists in the most obvious way during the first half of twentieth century. There was a sharp conflict between two perspectives: one held fast to the Kraepelinian view that every kind of affective disorder could be put under the allinclusive category, manic-depressive insanity (or psychosis); and the other objected to such a unitarian standpoint, emphasizing the necessity of distinguishing between severe and mild cases depending on the intensity of symptoms and drawing a line between endogenous and

20) Lancet, 14 May 1927. 
HWANG Hye Jean : Towards Modern Depressive Disorder: Professional Understanding of Depression in Interwar Britain

exogenous disorders based on the cause of depression. The debate on the classification of depression attracted leading psychiatrists and largely contributed to the atmosphere of this medical branch during the interwar years.

'The great British debate' began with the British Medical Association's annual meeting of 1926 in Nottingham. At the opening of the section for neurology and psychology, Edward Mapother, the medical superintendent of the Maudsley Hospital, presented his article, which advocated the Kraepelinian umbrella concept, manic-depressive psychosis. ${ }^{21)}$ He claimed that 'the distinction between neuroses and psychoses had neither basis nor meaning', although admitting that it grew 'out of the practical need and custom' (Mapother, 1926). According to him, various types of depression should be interpreted as located on a continuum rather than as discrete disorders, faithfully following Kraepelinian nosology (Jackson, 1986: 212-213). Mapother's presentation was followed by a furious discussion focusing on the classification of depression. The chairman of this section, Edward Farquhar Buzzard from the Royal College of Physicians, found Mapother's claim 'controversial and perhaps even provocative'. ${ }^{22)}$

21) However, Mapother's support for the concept of manic-depressive insanity in the meeting did not mean that he completely stood by Kraepelinian psychiatry. According to Rhodri Hayward, Mapother was sceptical about the existence of the discrete disease categories in psychopathology. He argued that the categories were just convenient fictions and believed such diagnoses underestimated the psychobiological complexity of the patient. Furthermore, he made his anti-Kraepelin stance clear in his lecture in the late 1930s, by supporting the continuity of all forms of mental disorder (Hayward, 2010: 71-74).

22) E. F. Buzzard was a leading physician in the field of neurology and psychiatry at his time. He contributed to improvement in the understanding of 'shell-shock' during the First World War, and built up his reputation by publishing textbooks and teaching in major institutions, such as the Royal College of Physicians, after the War. He was appointed as physician-extraordinary to King George V in 1923, became KCVO in 1927, and was created a baronet two years later. In 1928, he was appointed Regius 
HWANG Hye Jean : Towards Modern Depressive Disorder: Professional Understanding of Depression in Interwar Britain

He particularly refuted the speaker's argument that neurosis should be regarded as one of the subdivisions of the manic-depressive psychoses, as he regarded 'anxiety neurosis' as a discrete disorder. Then, T. A. Ross from Cassel Hospital came out against Mapother. He stood up for the essential differences between the psychoses and psychoneuroses, which was called a 'useless exercise' by the presenter. R. D. Gillespie from Guy's Hospital suggested a new way to divide affective disorders, adopting a nascent concept called 'reactiveness' (Mapother, 1926). ${ }^{23)}$ The fierce and prolonged discussion ended with Mapother's brief closing comment, with no consensus achieved.

The controversy did not end here, and British psychiatrists persisted in stating their own opinions, mostly through articles. In 1929 Gillespie published a long paper in Guy's Hospital Reports, in which he divided depression cases into two main groups: 'reactive' and 'autonomous' depressions (Gillespie, 1929). ${ }^{24)}$ According to this dichotomy, the former exhibited 'a host of psychoneurotic symptoms', including anxiety and worry, and 'the central feature' of cases falling into this group was 'responsiveness to influence, both external and internal' (Shorter, 2005: 84). Patients in the latter group by contrast showed 'no reactivity'. Depression cases falling into this category exhibited such varied symptoms that Gillespie found them constituting a 'heterogeneous group', but they were

Professor of Medicine at the University of Oxford, which was said to be 'the pinnacle of his career'; 'Farquhar Buzzard', Oxford Dictionary of National Biography, http:// dx. doi. org/10. 1093/ref:odnb/32226. Accessed 30 March 2017.

23) The five groups Gillespie suggested were manic-depressive disorders, reactive mood disorders, affective episodes in psychopathic personalities, psychoneurotic mood disorders, and miscellaneous groups.

24) However, Gillespie identified a limited number of 'involutional' depression cases, not falling into reactive or autonomous depression, which was mostly ignored by contemporary psychiatrists and psychiatric historians. 
all attributable to the 'apparent manic-depressive heredity' (Gillespie, 1929). Within this framework, the concept of 'reactivity' held the central position, the origin of which has been explained in several ways (Jackson, 1986: 212-213). Berrios, for example, emphasizes the influence of John T. MacCurdy, a Canadian psychiatrist, with whom Gillespie worked in collaboration at Cambridge University between 1927 and 1929. Gillespie, furthermore, had already mentioned MacCurdy's research at the British Medical Association's meeting when attacking Mapother's unitarian view (Berrios, 1996: 318). Stanley W. Jackson points out that Johannes Lange, Kraepelin's student and colleague, was a major influence, whereas Edward Shorter notes the fact that Gillespie had trained in Baltimore under the guidance of Adolf Meyer in his earlier career (Jackson, 1986: 212-213; Shorter, 2005: 177-178). However, no matter what the origin was, one thing seems obvious that in Britain the 'reactive-autonomous' dichotomy began with Gillespie. His deep involvement made this debate more like a competition between 'two big authorities' in London, Guy's Hospital and the Maudsley (Shorter, 2005: 84).

In the following year Buzzard chaired another discussion at the annual conference of Royal Society of Medicine. The subject of this meeting was 'the milder forms' of manic-depressive psychosis. In its Proceedings, Buzzard himself distinguished neurotic from psychotic depression, specified main differences between the two types and deplored the 'absence of proper guidance for practitioners' on milder disorders despite their prevalence. He also emphasized the difficulty of diagnosing mild forms of psychosis: 'the milder the form, the more difficult the diagnosis' (Buzzard, 1930). After his presentation, H. Crichton Miller from the Tavistock Clinic suggested the use of another discrete term 'cyclothymia' 
HWANG Hye Jean : Towards Modern Depressive Disorder: Professional Understanding of Depression in Interwar Britain

as a synonym for 'milder manifestations' in order to distinguish them from severe cases. In this session, the participants appeared to agree implicitly with the necessity of making a clear distinction between mild mood disorders and manic-depressive disorders, and to assume that affective disorders could be categorized into sub-groups according to severity. However, Miller's proposal failed to gain enough support from them. 25)

In the 1930s Lewis of the Maudsley took part in the debate and, subsequently, reignited the issue. Throughout the decade he published a series of articles on melancholia and depression, including "Melancholia: A Clinical Survey of Depressive States' in 1934 and 'Melancholia: Prognosis Study and Case-Material' in 1936. Among them, 'States of Depression: Their Clinical and Etiological Differentiation' published in 1938 dealt with the subject of classification head on. Here he concluded 'we have no sure means distinguishing' the numerous cases so that we 'must deny ourselves the ease of a simple classification'. In addition, he warned against the 'deceptive ease and deceptive simplicity' that psychiatrists might gain by adopting any arbitrary classification (Lewis, 1938: 875-878). By this assertion, Lewis showed himself as following his senior colleague, Mapother, and the unitarian perspective on manicdepressive disorder. The debate did not end with either Lewis or the outbreak of another World War. When R. E. Kendell published a review article on this subject in 1976, he commenced by stating that 'during the last fifty years, and particularly the last twenty, innumerable different

25) The unfamiliar term was never repeated during the session and even after the meeting it was rarely found in expert literature. The term 'cyclothymia' was not an invention of Miller himself. In 1882, Karl Kahlbaum coined the word to mean 'a circular mood disorder' (Shorter, 2005: 81-82, 152). 
HWANG Hye Jean : Towards Modern Depressive Disorder: Professional Understanding of Depression in Interwar Britain

classifications of depressive illness have been proposed' (Kendell, 1976).

The British debate on the classification of depression during the interwar years is a reflection of the larger situation which British psychiatry faced. It also shows from whence early-twentieth-century psychiatry came and where it went. The debate, therefore, has to be understood as the result of various factors, coming from both within and outside of British psychiatry, working together. The direct cause was "the uncertainties concerning the nosological position of what was called 'neurotic, reactive, exogenous, psychogenic, or constitutional affective disorders' (Berrios: 1995, 397399). The view that such disorders should be re-identified, re-named and re-classified resulted from various changes that early-twentieth-century psychiatry underwent and achieved. In explaining the origin of the great British debate, Berrios emphasizes four factors that worked together: clinical observation; challenge to Kraepelinian dichotomy; the growth of the psychodynamic hypothesis; and the influence of Meyerian psychiatry (Berrios, 1996; Gelder, 2003).

Among these determinants, the shift in clinical observation during the early twentieth century, especially during and after the First World War, has been frequently mentioned as a primary cause of the classification debate. During the nineteenth century, the classification of melancholia (and mania) had not been difficult, as most of the cases had been collected 'from the severe end of the affective disorders', in other words certified patients (Berrios, 1996, 316-317). In the early twentieth century, especially in the interwar years, the main interest of psychiatry moved from major, severe and relatively rare mental diseases to minor, mild and comparatively common cases (Porter, 1996: 395-396). The venue for the care of mental illness diversified, with the coming of psychiatric units 
HWANG Hye Jean : Towards Modern Depressive Disorder: Professional Understanding of Depression in Interwar Britain

in general hospitals, out-patient clinics, private practices and after-care facilities, all of which promoted the chance to access to varied medical service outside the asylum (Busfield, 2014: 638). Now, psychiatrists faced an increasing number of cases which could have been identified as 'hypochondriasis, hysteria, neurasthenia or psychasthenia', and diagnosed most of them as depression or non-psychotic manic-depressive state (Berrios, 1995: 399).26) Under the circumstances, psychiatrists came to find Kraepelinian nosology, which had been intrinsically based on data collected in Victorian-style asylums, unsatisfactory, and demanded an alternative framework that could be used to cover the majority of cases which could not be identified precisely by applying the manic-depressive insanity concept (Berrios, 1996: 316-317).

International influence also gave major impetus to the debate. Western European counterparts were a traditional and effective stimulant to British psychiatrists. The German concept of endogenous and exogenous depression, which originated with Paul J. Möbius in 1890s, filtered into Britain in the 1920s and helped ignite the debate (Jackson, 1986: 211212; Shorter, 2005: 84-85). As mentioned earlier, the concept of reactive

26) Berrios pays special attention to the diagnostic concept of neurasthenia and argues that 'the dismembering' of the notion exerted a huge impact on the British debate on classification. Neurasthenia itself has a complex history, which cannot be summarized in a few lines. To understand its position in British psychiatry, see Simon Wessely, "Neurasthenia and Fatigue Syndromes," German E. Berrios and Roy Porter, eds., A History of Clinical Psychiatry: The Origin and History of Psychiatric Disorders (London: Athlone, 1995), pp. 509-532; Mathew Thomson, "Neurasthenia in Britain: An Overview," Marijke Gijswijt-Hofstra and Roy Porter, eds., Cultures of Neurasthenia from Beard to the First World War (Amsterdam: Rodopi, 2001), pp. 77-95; Michael Neve, "Public Views of Neurasthenia: Britain, 1880-1930," Gijswijt-Hofstra and Porter, eds., Cultures of Neurasthenia, pp.141-160; Ruth E. Taylor, "Death of Neurasthenia and its Psychological Reincarnation," British Journal of Psychiatry 179-6 (2001), pp. 550-557. 
HWANG Hye Jean : Towards Modern Depressive Disorder: Professional Understanding of Depression in Interwar Britain

melancholia, suggested by Lange, was also taken seriously in Britain. British psychiatry also received a new stimulus from across the Atlantic, as American psychiatry emerged as a major power in this field. Meyer, who articulated his grave reservations concerning the Kraepelinian nosology and considered psychiatric disorders as a maladaptive reaction pattern, was particularly influential in Britain, although he was far from being an international figure. His doctrine and practice were not only main factors stimulating the British debate, but also exerted huge influence upon young British psychiatrists as he was involved in their training. 27)

Meanwhile, the debate on the classification of depression became a feature of British psychiatry and distinguished it from other European countries. The debate coincided with a divergence in European psychiatry, which had hitherto been unified. Until the turn of the century, there had been a set of views on melancholia and depression generally accepted and circulated in expert psychiatric circles across Europe. Most psychiatrists, irrespective of nationality, had considered the disorder as an essentially emotional disease, a result of brain lesions, and morbidity under the huge influence of heredity. From the 1920s, however, medical professions of major countries began to show their peculiarities, by selectively paying attention to certain aspects. French professionals were more concerned about heredity and environmental influence, while Germans focused on constitution and personality (Berrios, 1996:

27) For instance, Meyer trained Aubrey Lewis of the Maudsley as a postdoctoral fellow between 1913 and 1915, and guided as his first chief resident D. K. Henderson, who later became a professor of psychiatry at Edinburgh. Meyer was also involved in training R. D. Gillespie of Guy's Hospital, who wrote one of the most successful textbooks in this field with Henderson (Jackson, 1986: 195-202; Shorter, 2005: 101; Hayward, 2014: 69-70). 
HWANG Hye Jean : Towards Modern Depressive Disorder: Professional Understanding of Depression in Interwar Britain

316). British doctors, as stated above, concentrated on classification and severity of depression, the core subject of the debate. To summarize, the fierce debate determined the trajectory of British psychiatry during the interwar period and afterwards, at the same time it reflected the more general medical context.

\section{Conclusion}

In a nutshell, depression in the interwar decades could not yet be called as 'modern'. During the nineteenth century, depression had been reconceptualized, and came to be equipped with a clear definition as a medical concept around the turn of the century. In the interwar years, the diagnosis achieved some progress, notably in terms of terminology, approaching its modern form, but its status as a discrete mental disorder was far from secure. Melancholia, its predecessor, did not disappear easily, even after it was officially abolished in taxonomy scheme and was defeated by depression in terms of word frequency. Furthermore, neighboring notions, such as neurasthenia and cyclothymia, encroached on its domain, aggravating the conceptual confusions and causing practical problems. The classification of depression was a conundrum, in which many of the leading psychiatrists (and major mental institutions) were involved. As imagined, the complex and confusing situation could not help but recur in everyday practice. Thus, the early twentieth century should be recognized as a part of the long process by which depression achieved its modernity, beginning in the early nineteenth century and ending only in the post-war era.

Such explanation about depression may well be applied to psychiatry 
HWANG Hye Jean : Towards Modern Depressive Disorder: Professional Understanding of Depression in Interwar Britain

in those decades. Although this medical branch experienced a series of changes, some of which could be considered innovative, modern psychiatry was around the corner.28) Well into the 1930s, British psychiatry was still under the strong influence of the nineteenth-century medical tradition, regarding diagnosis and treatment, as well as the whole system. Thus, in order to understand early- and mid-twentiethcentury British psychiatry, Victorian customs need to be taken seriously and continuities noted. Depression, one of the most prevalent mental illnesses already around the outbreak of the First World War, gives a perfect instance illustrating the characteristics of psychiatry in those years.

28) The advent of modern psychiatry in Britain was to be realized only through additional fundamental changes and developments, inside and outside the medical department, after the Second World War: the organization of the NHS in 1948 and subsequent integration of psychiatry into general medicine; the publication of the Diagnostic and Statistical Manual of Mental Disorders in 1952; the broad application of new therapeutic techniques, mostly having invented during interwar years, notably ECT and later pharmaceutical interventions, in psychiatric practice; and the Mental Treatment Act of 1959, the major impact of which was to move psychiatric treatment away from institutional care to community care. 
HWANG Hye Jean : Towards Modern Depressive Disorder: Professional Understanding of Depression in Interwar Britain

\section{REFERENCES}

〈Primary Sources〉

Manuscript Sources

Bethlem Royal Hospital Archives and Museums (BRHAM)

- Maudsley Hospital, Medical Superintendents' Annual Reports

- Maudsley Hospital, Patient Casenotes

London Welcome Institute of History of Medicine Archives (LWIHM)

- Holloway Sanatorium, Case Book: Females

Newspapers and Periodicals

The American Journal of Surgery

British Journal of Psychiatry (Journal of Mental Science)

Lancet

Contemporary Articles, Books, Pamphlets and Speeches

Buzzard, E. F., "Discussion on the Diagnosis and Treatment of the Milder Forms of the Manic-Depressive Psychosis," Proceedings of the Royal Society of Medicine 23-6 (1930), pp. 881-895.

Gillespie, R. D., "The Clinical Differentiation of Types of Depression," Guy's Hospital Reports 79 (1929), pp. 306-344.

Henderson D. K., and R. D. Gillespie, A Text-Book of Psychiatry for Students and Practitioners (London: Oxford University Press, 1927).

Kendell, R. E., "The Classification of Depression: A Review of Contemporary Confusion," British Journal of Psychiatry 129:1 (1976), pp. 15-28.

Kraepelin, Emil, Manic-Depressive Insanity and Paranoia, George Robertson, ed., Mary Barclay, trans. (Edinburgh: Livingstone, 1921).

Lewis, Aubrey, "Melancholia: A Clinical Survey of Depressive States," Journal of Mental Science 80-329 (1934), pp. 277-278.

"Melancholia: Prognosis Study and Case-Material," Journal of Mental Science 82-340 (1936), pp. 488-558.

"States of Depression: Their Clinical and Aetiological Differentiation," British Medical Journal 2-4060 (1938), pp. 875-878. 
HWANG Hye Jean : Towards Modern Depressive Disorder: Professional Understanding of Depression in Interwar Britain

Mapother, Edward, "Discussion on Manic-Depressive Psychosis," British Medical Journal 2-3436 (1926), pp. 872-879.

Royal College of Physicians of London, Nomenclature of Disease (4th edn, London, 1906)

Tuke, D. H., Dictionary of Psychological Medicine (London: Churchill, 1892).

\section{〈Secondary Sources >}

Berrios, German E., "Melancholia and Depression during the Nineteenth Century: A Conceptual History," British Journal of Psychiatry 153-3 (1988), pp. 298-304. "Mood Disorders," German E. Berrios and Roy Porter, eds., A History of Clinical Psychiatry: The Origin and History of Psychiatric Disorders (London: Athlone, 1995), pp. 384-408.

, The History of Mental Symptoms: Descriptive Psychopathology since the Nineteenth Century, (Cambridge: Cambridge University Press, 1996).

Busfield, Joan, "Mental Illness," Roger Cooter and John Pickstone, eds., Medicine in the Twentieth Century (London: Routledge, 2014), pp. 633-652.

Gelder, Michael, "Introduction: Adolf Meyer and his Influence on British Psychiatry," History of Psychiatry 14-4 (2003), pp. 475-492.

Hayward, Rhodri, "Germany and the Making of 'English' Psychiatry: The Maudsley Hospital, 1908-1939," Volker Roelcke, Paul Weindling, and Louise Westwood, eds., International Relations in Psychiatry: Britain, Germany, and the United States to World War II (Rochester NY: University of Rochester Press, 2010), pp. 67-90.

, The Transformation of the Psyche in British Primary Care, 1880-1970 (London: Bloomsbury, 2014).

Horwitz, Allan V., and Jerome C. Wakefield, The Loss of Sadness: How Psychiatry Transformed Normal Sorrow into Depressive Disorder (Oxford: Oxford University Press, 2007).

Jackson, Stanley W., Melancholia and Depression: From Hippocratic Times to Modern Times (London: Yale University Press, 1986).

"A History of Melancholia and Depression," Edwin R. Wallace and John Gach, eds., History of Psychiatry and Medical Psychology (New York: Springer, 2008), pp. 443-460. 
Jansson, Åsa, "Mood Disorder and the Brain: Depression, Melancholia, and the Historiography of Psychiatry," Medical History 55-3 (2011), pp. 393-399.

"From Statistics to Diagnostics: Medical Certificates, Melancholia, and 'Suicidal Propensities' in Victorian Psychiatry," Journal of Social History 46-3 (2013), pp. 716-731.

Jones, Kathleen, Asylums and After: A Revised History of the Mental Health Services, From the Early 18th Century to the 1990s (London: Athlone, 1993).

Lawlor, Clark, From Melancholia to Prozac: A History of Depression (Oxford: Oxford University Press, 2012).

Long, Vicky, Destigmatising Mental Illness? Professional Politics and Public Education in Britain, 1870-1970 (Manchester: Manchester University Press, 2014).

Misbach, Judith, and Henderikus Stam, "Medicalising Melancholia: Exploring Profiles of Psychiatric Professionalisation," Journal of the History of the Behavioural Science 42-1 (2006), pp. 41-59.

Neve, Michael, "Public Views of Neurasthenia: Britain, 1880-1930," Marijke GijswijtHofstra and Roy Porter, eds., Cultures of Neurasthenia from Beard to the First World War (Amsterdam: Rodopi, 2001), pp.141-160

Porter, Roy, "Two cheers for Psychiatry! The Social History of Mental Disorder in Twentieth Century Britain," Hugh Freeman and German E. Berrios, eds., 150 Years of British Psychiatry, Vol. II: The Aftermath (London: Athlone, 1996), pp. 383-403.

Radden, Jennifer, Moody Minds Distempered: Essays on Melancholy and Depression (Oxford: Oxford University Press, 2009).

Shorter, Edward, A History of Psychiatry: From the Era of the Asylum to the Age of Prozac (New York: Wiley, 1997).

A Historical Dictionary of Psychiatry (Oxford: Oxford University Press, 2005).

Showalter, Elaine, The Female Malady: Women, Madness, and English Culture, 18301980 (London: Virago, 1987).

Taylor, Ruth E., "Death of Neurasthenia and its Psychological Reincarnation," British Journal of Psychiatry 179-6 (2001), pp. 550-557.

Thomson, Mathew, Psychological Subjects: Identity, Culture, and Health in TwentiethCentury Britain (Oxford: Oxford University Press, 2006).

"Neurasthenia in Britain: An Overview," Marijke Gijswijt-Hofstra and Roy 
HWANG Hye Jean : Towards Modern Depressive Disorder: Professional Understanding of Depression in Interwar Britain

Porter, eds., Cultures of Neurasthenia from Beard to the First World War (Amsterdam: Rodopi, 2001), pp. 77-95.

Varga, Somogy, "From Melancholia to Depression: Ideas on a Possible Continuity," Philosophy, Psychiatry, and Psychology 20-2 (2013), pp. 141-155.

Wessely, Simon, "Neurasthenia and Fatigue Syndromes," German E. Berrios and Roy Porter, eds., A History of Clinical Psychiatry: The Origin and History of Psychiatric Disorders (London: Athlone, 1995), pp. 509-532.

투고일: 2019.07.31 심사일: 2019.10.19 게재확정일: 2019.11.27 


\title{
Towards Modern Depressive Disorder: Professional Understanding of Depression in Interwar Britain
}

\author{
Hwang, Hye Jean*
}

This article examines the way in which British psychiatrists defined, categorized, and applied depression in the period between the two World Wars. To analyze the professional understanding and application of the notion, various expert literatures will be analyzed, such as textbooks, medical journals, and medical documents kept in daily practice. Through the analysis, this article suggests that in the interwar decades, the status of depression as a distinct mental disorder was far from established in terms of its definition, terminology, and classification, although the disorder had already become the most prevalent mental illness by the turn of the century. Also, this article argues that the early twentieth century should be recognized as a part of the long evolution through which depression achieves its modernity, beginning in the early twentieth century and ending in the post-war era. Such findings about a specific psychiatric

\footnotetext{
* * Lecturer, Department of Western History, Seoul National University, Korea
} Received: Jul. 31, 2019; $\quad$ Reviewed: Oct. 19, 2019; Accepted: Nov. 27, 2019 
HWANG Hye Jean : Towards Modern Depressive Disorder: Professional Understanding of Depression in Interwar Britain

diagnosis can be applied to the explanation of contemporary psychiatry. At least before the Second World War, British psychiatry had not yet entered into its modern phase and was still under the strong influence of the Victorian medical tradition. Thus, this article claims that in order to understand British psychiatry and its characteristics against this historical background, continuity should be stressed rather than modernity.

Keywords: depression, depressive disorder, melancholia, Emil Kraepelin, British psychiatry, interwar psychiatry, the Great British Debate 
